\title{
Pharmacological and toxicological effects of co-exposure of human gingival fibroblasts to silver nanoparticles and sodium fluoride
}

This article was published in the following Dove Press journal:

International Journal of Nanomedicine

2 April 2014

Number of times this article has been viewed

\author{
Iwona Inkielewicz- \\ Stepniak ${ }^{1, *}$ \\ Maria Jose Santos- \\ Martinez ${ }^{2-4, *}$ \\ Carlos Medina ${ }^{2,4}$ \\ Marek W Radomski ${ }^{2,4}$ \\ 'Department of Medicinal Chemistry, \\ Medical University Gdansk, Debinki, \\ Poland; ${ }^{2}$ The School of Pharmacy \\ and Pharmaceutical Sciences, Panoz \\ Institute, Trinity College Dublin, \\ Dublin, Ireland; ${ }^{3}$ School of Medicine, \\ Trinity College Dublin, Dublin, Ireland; \\ ${ }^{4}$ Trinity Biomedical Sciences Institute, \\ Trinity College, Dublin, Ireland \\ *These authors contributed equally \\ to this work
}

Background: Silver nanoparticles (AgNPs) and fluoride (F) are pharmacological agents widely used in oral medicine and dental practice due to their anti-microbial/anti-cavity properties. However, risks associated with the co-exposure of local cells and tissues to these xenobiotics are not clear. Therefore, we have evaluated the effects of AgNPs and F co-exposure on human gingival fibroblast cells.

Methods: Human gingival fibroblast cells (CRL-2014) were exposed to AgNPs and/or F at different concentrations for up to 24 hours. Cellular uptake of AgNPs was examined by transmission electron microscopy. Downstream inflammatory effects and oxidative stress were measured by real-time quantitative polymerase chain reaction (PCR) and reactive oxygen species (ROS) generation. Cytotoxicity and apoptosis were measured by 3-(4,5-dimethylthiazol2-yl)-2,5-diphenyltetrazolium bromide (MTT) assay and real-time quantitative PCR and flow cytometry, respectively. Finally, the involvement of mitogen-activated protein kinases (MAPK) was studied using Western blot.

Results: We found that AgNPs penetrated the cell membrane and localized inside the mitochondria. Co-incubation experiments resulted in increased oxidative stress, inflammation, and apoptosis. In addition, we found that co-exposure to both xenobiotics phosphorylated MAPK, particularly p42/44 MAPK.

Conclusion: A combined exposure of human fibroblasts to AgNPs and F results in increased cellular damage. Further studies are needed in order to evaluate pharmacological and potentially toxicological effects of AgNPs and F on oral health

Keywords: nanoparticles, oxidative stress, apoptosis, inflammation, mitogen-activated protein kinases, matrix, metalloproteinases

\section{Introduction}

Despite the fact that demand for medical implants is growing worldwide, patients usually suffer from bacterial infections caused by these devices. In order to prevent such infections, the best approach is to deliver antimicrobial agents on the surface of the implant. Metallic silver has been used across civilizations for numerous medical conditions. ${ }^{1-3}$ Compared to other nonessential heavy metals, silver shows the highest antimicrobial efficacy against microorganisms. In addition, microbes are unlikely to develop resistance against silver, because the metal attacks a broad range of targets in the microorganism. Over the past few years, nanotechnology has been used for many medical applications, including dental practice, with the development of silver nanoparticles (AgNPs) as a useful tool. ${ }^{2,3}$ It is known that smaller silver nanoparticles have more antimicrobial effectiveness than larger silver nanoparticles. The increased antimicrobial activity of the
Correspondence: Carlos Medina

The School of Pharmacy and Pharmaceutical Sciences, Panoz Institute, Trinity College Dublin, College Green, Dublin 2, Ireland

Email carlos.medina@tcd.ie 
smaller nanoparticles is due to the fact that smaller particles penetrate more easily through cell membranes and cell walls, and that relative to larger nanoparticles, smaller particles have a greater surface area to volume ratio. ${ }^{1-5}$ Thus, silver compounds as nanoparticles have been widely used as dental restorative material, endodontic retrofill cements, dental implants, and as a caries inhibitory solution. ${ }^{2,3} \mathrm{Li}$ et $\mathrm{al}^{4}$ found that incorporation of AgNPs into Scotchbond Multi-Purpose bonding system (3M, St Paul, MN, USA) exerts potent antibacterial activity without adversely affecting the microtensile dentin bond strength and fibroblast viability. Despite the effectiveness that AgNPs have shown in dental practice, the toxicity of AgNPs has not yet been fully evaluated. ${ }^{5}$

Fluoride $(\mathrm{F})$ in various forms is the most popular active ingredient in dental products to prevent cavities as well as a commonly used agent in dental practice. On the other hand, F has been shown to be toxic, not only to the skeletal system, but also to the soft tissues by multiple mechanisms, such as enzyme activity inhibition, reactive oxygen and nitrogen species generation, impairment of the antioxidant defense system, induction of inflammation, and apoptosis. ${ }^{6-10}$

As AgNPs and F may be used concomitantly in dental practice, we studied the effects of co-exposure to these xenobiotics on human gingival fibroblasts. It is known that xenobiotic interaction may increase or decrease the toxic effect of one or many substances. ${ }^{10-12}$ Therefore, the effects of AgNPs and F co-exposure on cell viability, oxidative stress, and inflammation were evaluated in vitro.

\section{Materials and methods}

\section{Reagents}

The silver nanoparticles (nanoparticle water dispersion: $2 \mathrm{~nm}, 2,000$ ppm, colorless, and transparent) were obtained from US Research Nanomaterials (Houston, TX, USA). The fluoride solution was prepared using sodium fluoride (Sigma Aldrich, St Louis, MO, USA).

\section{Cell culture}

A CRL-2014 cell line was obtained from the American Type Culture Collection (ATCC-HBT-55) and maintained as a monolayer culture in $\mathrm{T}-75 \mathrm{~cm}^{2}$ tissue culture flasks. The cells were grown in Dulbecco's Modified Eagle's Medium (Sigma Aldrich), a high glucose medium (4.5 g/L) containing sodium pyruvate $(110 \mathrm{mg} / \mathrm{L})$, and supplemented with $10 \%$ fetal bovine serum, $6 \mu \mathrm{g} / \mathrm{mL}$ penicillin- $\mathrm{G}$, and 10 $\mu \mathrm{g} / \mathrm{mL}$ streptomycin. Cells were maintained at $37^{\circ} \mathrm{C}$ in a humidified atmosphere of $95 \% \mathrm{O}_{2}, 5 \% \mathrm{CO}_{2}$. When conflu- ent, cells were detached enzymatically with trypsin-EDTA and sub-cultured into a new cell culture flask. The medium was replaced every 2 days.

\section{Cell exposure to $\mathrm{F}$ or/and AgNPs}

The concentrations of AgNPs and F used in the experiments were carefully chosen according to the results obtained from preliminary experiments and literature data. ${ }^{10,13,14} \mathrm{AgNPs}$ ranging $1.5-5 \mathrm{~nm}$ are mostly used in dental practice. Therefore, we have carried out all experiments using $2 \mathrm{~nm}$ AgNPs.

The concentrations of AgNPs and F were selected based on the results of preliminary experiments. We found that $\mathrm{F}<1 \mathrm{mM}$ and AgNPs $<1.5 \mu \mathrm{g} / \mathrm{mL}$ did not induce significant effects in gingival fibroblasts. Therefore, the experiments were performed by combining the subthreshold concentrations of AgNPs and F to evaluate if co-exposure could lead to an enhanced toxicity effect.

The CRL-2014 cell line was treated with F $(0.5 ; 1$; $1.5 \mathrm{mM}-9.5 ; 19 ; 28.5 \mathrm{ppm}$, respectively) and/or AgNPs $(0.5 ; 1.5 ; 2.5 ; 3.5 \mu \mathrm{g} / \mathrm{mL})$ for 24 hours, except for Western blotting and PCR experiments ( 1 hour and 8 hours incubation time, respectively).

Fluoride was dissolved in serum-free culture medium. Test solutions of AgNPs were also prepared in serum-free medium. Immediately before use, NP solutions were vortexed for 1 minute to prevent aggregation following the manufacturer's instructions. Controls were prepared with an equivalent volume of media with neither F nor AgNPs.

\section{Cellular morphology}

The morphology of CRL-2014 cells in the presence of xenobiotics was visualized by phase-contrast microscopy (ALTRA20 microscopy and Cell^A Acquisition software; Olympus, Tokyo, Japan).

\section{Cellular uptake of AgNPs}

Ultrathin sections of cells were analyzed using transmission electron microscopy (TEM) to reveal the uptake and distribution of NPs. Briefly, cells seeded into 12 -well plates $\left(1.5 \times 10^{6}\right.$ cells/well) were treated with $\operatorname{AgNPs}(1.5 \mu \mathrm{g} / \mathrm{mL})$ for 24 hours. At the end of the incubation period, wells were washed with PBS to remove the excess of unbound NPs. Samples were first fixed in 2.5\% glutaraldehyde in 0.1 M Sørensen's phosphate buffer (Riedel-deHaën AG, Seelze, Germany) for 2 hours at room temperature and then fixed in 1\% osmium tetroxide (Oxkem Limited, Reading, UK) in Sørensen's phosphate buffer for 1 hour at room temperature. Subsequently, 
the specimens were dehydrated in a graded ethanol series, at $30 \%, 50 \%$, and $70 \%$. To enhance the contrast en bloc, staining with $2 \%$ uranyl acetate (Agar Scientific, Essex, UK) in $70 \%$ ethanol was performed and then the dehydration was continued with $90 \%$ and $100 \%$ ethanol. When dehydration was complete, samples were transferred from $100 \%$ ethanol to acetone, from acetone to a mixture of one part acetone and one part epoxy resin (TAAB-Epon; Agar Scientific, Essex, UK) for 1 hour. To complete the resin infiltration, the samples were placed in $100 \%$ resin at $37^{\circ} \mathrm{C}$ for 2 hours. Finally samples were embedded in resin, and stored at $60^{\circ} \mathrm{C}$ for 24 hours until polymerization was complete.

For orientation purposes, sections from each sample were cut at $1 \mu \mathrm{m}$, stained with toluidine blue, and examined by light microscopy (Leica DMLB; Leica Microsystems, Wetzlar, Germany).

From these survey sections, areas of interest were identified and ultrathin $(80 \mathrm{~nm})$ sections were obtained using a Leica EM UC6 ultramicrotome (Leica Microsystems). These sections were collected on 200-mesh thin bar copper grids, stained with uranyl acetate and lead citrate (Agar Scientific, Essex, UK), and examined by TEM (Tecnai G2 12 BioTWIN; FEI Company, Hillsboro, OR, USA) using an accelerating voltage of $120 \mathrm{kV}$. Images were recorded with a MagaView III camera (SIS, Münster, Germany).

\section{Intracellular ROS generation}

Briefly, the cells were seeded into 12 -well plates at a concentration of $1 \times 10^{6}$ cells/well; 24 hours after seeding, cells were exposed to different concentrations of $\mathrm{F}$ and/or AgNPs in serum-free media as above, then collected and incubated with $40 \mu \mathrm{M}$ of carboxy- $\mathrm{H}_{2}$ DCFDA (Molecular Probes, Eugene, OR, USA) for 15 minutes to assess ROSmediated oxidation of DCFDA to the fluorescent compound 2,7-dichlorofluorescein DCF. The fluorescence of oxidized DCF was measured on a plate reader (FLUOstar OPTIMA; BMG Labtech, Aylesbury, UK) at excitation and emission wavelengths of 485 and $530 \mathrm{~nm}$, respectively.

\section{Lipid peroxidation}

CRL-2014 cells were plated into 24-well plates at a density of $1.5 \times 10^{6}$ cells per well in complete medium. Pre-confluent cells were then exposed to different concentrations of $\mathrm{F}$ and/or AgNPs in serum-free medium as above for 24 hours at $37^{\circ} \mathrm{C}$. Malondialdehyde (MDA), a measure of lipid peroxidation, was measured using an OxiselectTMTBARS Assay kit (Cell Biolabs Inc., Cambridge, UK) following the manufacturer's instructions. Fluorescent measurements were recorded on a plate reader (FLUOstar OPTIMA) at excitation and emission wavelengths of 485 and $530 \mathrm{~nm}$, respectively. The concentration of MDA in test samples was calculated using MDA standards as the reference. The concentration of MDA in F and/or AgNPs-treated cells is presented as the fold increase of MDA production over the control (untreated cells).

\section{Total antioxidant capacity}

For determining cellular total antioxidant capacity, posttreatment cells were washed with PBS and suspended in $200 \mu \mathrm{L}$ of ice-cold lysis buffer and sonicated. The lysate was centrifuged at 10,000 rpm for 10 minutes, and the protein concentration of the supernatant fraction was determined by the Bradford method. ${ }^{13}$ The Trolox equivalent antioxidant activity was measured by assessing the ability of hydrogen-donating antioxidants to scavenge the radical cation generated by $2,2^{\prime}$ azino-bis(3-ethylbenzothiazoline)-6-sulfonic acid. Absorbance was recorded at $570 \mathrm{~nm}$ (FLUOstar, OPTIMA).

\section{Cell viability was measured by MTT assay}

CRL cells were seeded in triplicate at a density of $10^{4}$ cells $/ 100 \mu \mathrm{L}$ of cell culture medium into a $96-w e l l$. The next day, CRL-2014 cells were exposed to different concentrations of F and/or AgNPs as above for 24 hours. This assay evaluates mitochondrial activity (assesses cell growth and cell death) and is performed by adding a premixed optimized dye solution to culture wells. Absorbance was recorded at $570 \mathrm{~nm}$ (FLUOstar OPTIMA). Results from the treatment groups were calculated as a percentage of control values (unexposed cells) according to the following equation: \% cytotoxicity $=$ (experimental absorbance [abs] $570 \mathrm{~nm}$ of exposed cells $/$ abs $570 \mathrm{~nm}$ of unexposed cells) $\times 100$.

\section{Flow cytometry analysis of apoptosis}

The Annexin V-FITC apoptosis detection kit (BD Pharmingen, San Jose, CA, USA) was used to detect apoptosis according to the manufacturer's instructions. Briefly, cells $\left(5 \times 10^{6}\right)$ were seeded into $25 \mathrm{~cm}^{2}$ tissue culture flasks; 24 hours after seeding, cells were treated as described, then collected and washed twice with cold PBS. Five microliters of Annexin V and $2.5 \mu \mathrm{L}$ of PI (propidium iodide) were added to the cells, which were resuspended in binding buffer. The cells were gently shaken while incubating for 15 minutes at room temperature in the dark. Cells were further diluted with $1 \times$ binding buffer and analyzed using a BD FACSArray (BD Biosciences, San Jose, CA, USA). Ten thousand specific events were analyzed. 


\section{Western blotting}

Western blotting was used in order to investigate the mitogen-activated protein kinases (MAPK) pathways. Briefly, CRL-2014 cells were exposed to $1.5 \mu \mathrm{g} / \mathrm{mL}$ AgNPs and/or $1 \mathrm{mM} \mathrm{F}$ for 60 minutes. Afterwards, conditioned media were discharged and attached cells rinsed (phosphate buffered saline $[\mathrm{PBS}] \times 3$ ), detached, and homogenized. Following electrophoresis, proteins were transferred onto nitrocellulose membrane (Protran, Schleicher and Schuell; Dassel, Germany) and detected using rabbit anti-phosphorylated p38, p42/44, and JNK antibodies (Cell Signaling, Hitchin, UK). When appropriate, blots were stripped and analyzed for $\beta$-actin (Sigma Aldrich) as an internal control and for total p38, p42/44, and JNK (Cell Signaling).

\section{Real-time quantitative polymerase chain reaction (PCR)}

Cells were treated with different concentrations of $\mathrm{F}$ and/or AgNPs for 8 hours. Controls without $\mathrm{F}$ and AgNPs were also prepared. Following incubation, the cells were washed twice with PBS. DNA-free RNA was isolated using the Ambion $^{\circledR}$ RiboPureTM kit (Huntingdon, UK) according to the supplier's recommendations. Thereafter, isolated RNA in each sample was quantified using a NanoDrop ${ }^{\circledR}$ ND-1000 spectrophotometer (Fisher Scientific, Dublin, Ireland). An equal quantity of total DNA-free RNA from each sample was reverse-transcribed using a high-capacity cDNA reverse transcription kit (Applied Biosystems, Warrington, UK). Reverse transcription was performed using a Realplex ${ }^{2}$ Mastercycler (Eppendorf, Cambridge, UK). Finally, an equal quantity of total complementary DNA (cDNA) of each sample was used to perform real-time quantitative PCR in duplicate, with predesigned Applied Biosystems TaqMan ${ }^{\circledR}$ gene expression assays for MMP-9, IL-8, IL-6, BAX, and Bcl-2 along with Applied Biosystems TaqMan ${ }^{\circledR}$ Universal PCR Master Mix. In all experiments, 18S ribosomal RNA (rRNA) was used as an internal control. Real-time quantitative PCR was performed using a Realplex ${ }^{2}$ Mastercycler. The expression of each gene within each sample was normalized against $18 \mathrm{~S}$ rRNA expression and expressed relative to the control sample using the formula $2^{-(\Delta \Delta \mathrm{Ct})}$, in which $\Delta \Delta \mathrm{Ct}=(\mathrm{Ct}$ mRNA $-\mathrm{Ct} 18 \mathrm{~S}$ rRNA) sample - (Ct mRNA - Ct 18S rRNA) control.

\section{Zymography}

Briefly, conditioned media of cells treated as above were collected after 24 hours and protein concentration assessed by the Bradford method. ${ }^{15}$ Briefly, samples were subjected to $10 \%$ sodium dodecyl sulfate-polyacrylamide gel electrophoresis (SDS-PAGE) with copolymerized gelatin $(0.2 \%)$, (Sigma
Chemical Co, St Louis, MO, USA). After electrophoresis, the gels were washed with $2 \%$ Triton X-100 (two times, 20 minutes each), and then incubated in development buffer (50 mmol/L Tris $\mathrm{HCl}, 200 \mathrm{mmol} / \mathrm{L} \mathrm{NaCl}, 10 \mathrm{mmol} / \mathrm{L} \mathrm{CaCl}_{2}$, and $1 \mathrm{mmol} / \mathrm{L} \mathrm{ZnCl}_{2}, \mathrm{pH}=7.5$ ) at $37^{\circ} \mathrm{C}$ overnight. A conditioned medium of HT-1080 human fibrosarcoma cells was used as internal control. After incubation, gels were fixed and stained in $40 \%$ methanol, $10 \%$ acetic acid, and $0.1 \%(\mathrm{wt} / \mathrm{v})$ Coomassie Brilliant Blue for 1 hour and then de-stained.

\section{Statistical analysis}

All data are presented as the mean \pm standard error of three independent experiments. Statistical analysis of the mean difference between multiple groups was determined by one-way analysis of variance (ANOVA) followed by Tukey-Kramer multiple comparison tests, and between two groups by twotailed Student's $t$-tests. A $P$-value $<0.05$ was considered to be statistically significant. All statistical analyses were performed using GraphPad Prism (v5.00 for Windows; GraphPad Software, San Diego, CA, USA).

\section{Results}

\section{Uptake of AgNPs by CRL-20 I 4 cells}

TEM was used to study AgNPs-gingival fibroblast cell interactions and uptake. After 24 hours of incubation, AgNPs both
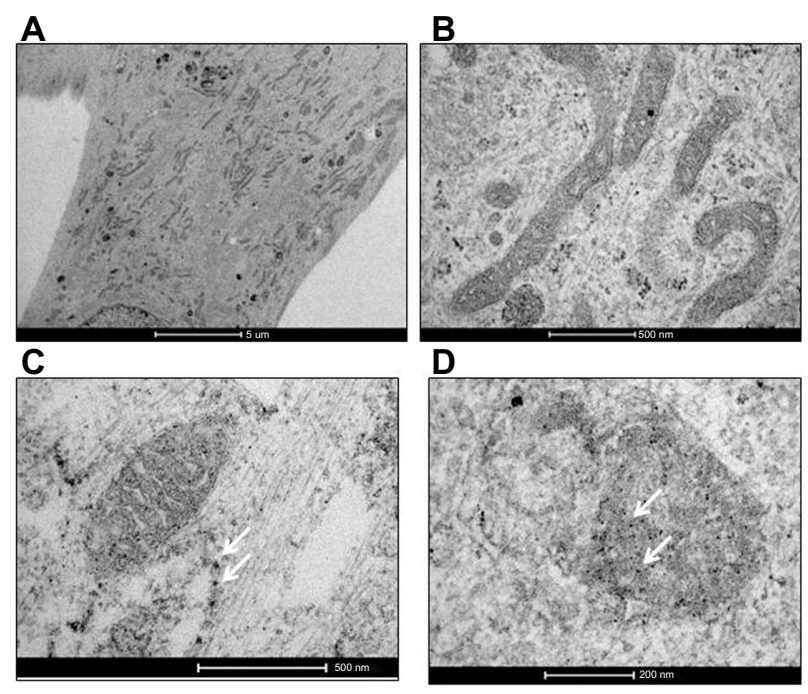

Figure I Uptake of AgNPs by CRL-2014 cells. (A) Low- and (B) high-power TEM images of untreated cells (controls); (C) low- and (D) high-power TEM images of treated cells. As shown by TEM, after exposure of cells to AgNPs, NPs were internalized and distributed within the cell (white arrows) (C). AgNPs were mainly found in the mitochondria (white arrows) (D). Some NPs agglomerates are found (C and D). Notes: Original magnification in $(\mathbf{A})$ is $4,200 \times$, whereas original magnification in (B) is $43,000 \times$; original magnification in (C) is $43,000 \times$, whereas original magnification in $(D)$ is $87,000 \times$.

Abbreviations: AgNPs, silver nanoparticles; NPs, nanoparticles; TEM, transmission electron microscopy. 
in the presence and absence of $\mathrm{F}$ were taken up, internalized, and distributed into CRL-2014 cells (Figure 1). They were mainly found in the mitochondria forming agglomerates (Figure 1).

\section{AgNPs and $\mathrm{F}$ induce ROS generation and lipid peroxidation in CRL-20I4 cells}

As AgNPs were found in the mitochondria, we next studied endogenous ROS generation. We found that both AgNPs and $\mathrm{F}$ were able to induce ROS generation in a concentration-dependent manner. This effect was enhanced when cells were co-exposed to AgNPs and F (Figure 2A). Lipid peroxidation was also studied, as this degradation process could be initiated by ROS generation. Indeed, both AgNPs and $\mathrm{F}$ induced MDA production, an effect that was even greater when cells were co-exposed to AgNPs and F (Figure 2B).

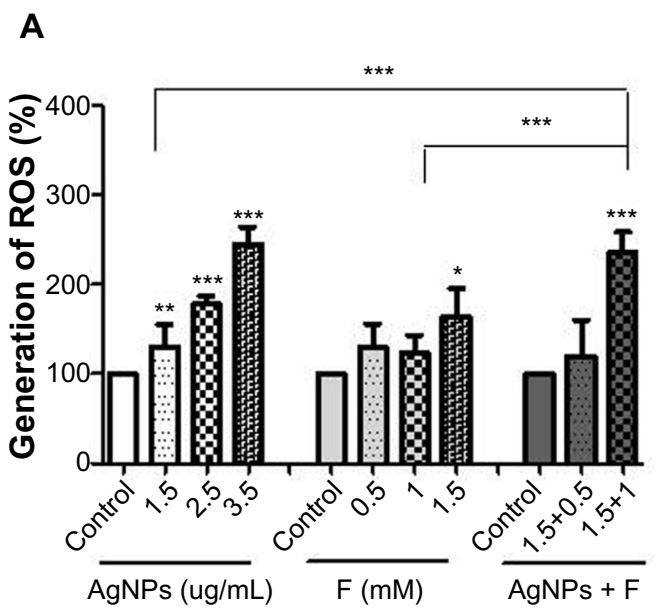

\section{AgNPs and $F$ decrease total antioxidant capacity in CRL-20I 4 cells}

As increased intracellular production of ROS is likely to impair antioxidant defenses, we then studied the total antioxidant capacity (TAC) of human gingival fibroblasts. We found that both AgNPs and F were able to reduce TAC, an effect that was enhanced when CRL-2014 cells were co-exposed to AgNPs and F (Figure 2C).

\section{AgNPs and $\mathrm{F}$ co-exposure decreases viability of CRL-20 I 4 cells}

We then investigated if increased oxidative stress was associated with cell damage. AgNPs and F were found to reduce cell viability in a concentration-dependent manner (Figure 3A). This effect was enhanced when CRL-2014 cells were co-exposed to AgNPs and F (Figure 3A). Furthermore, we studied if decreased cellular viability could be linked

B
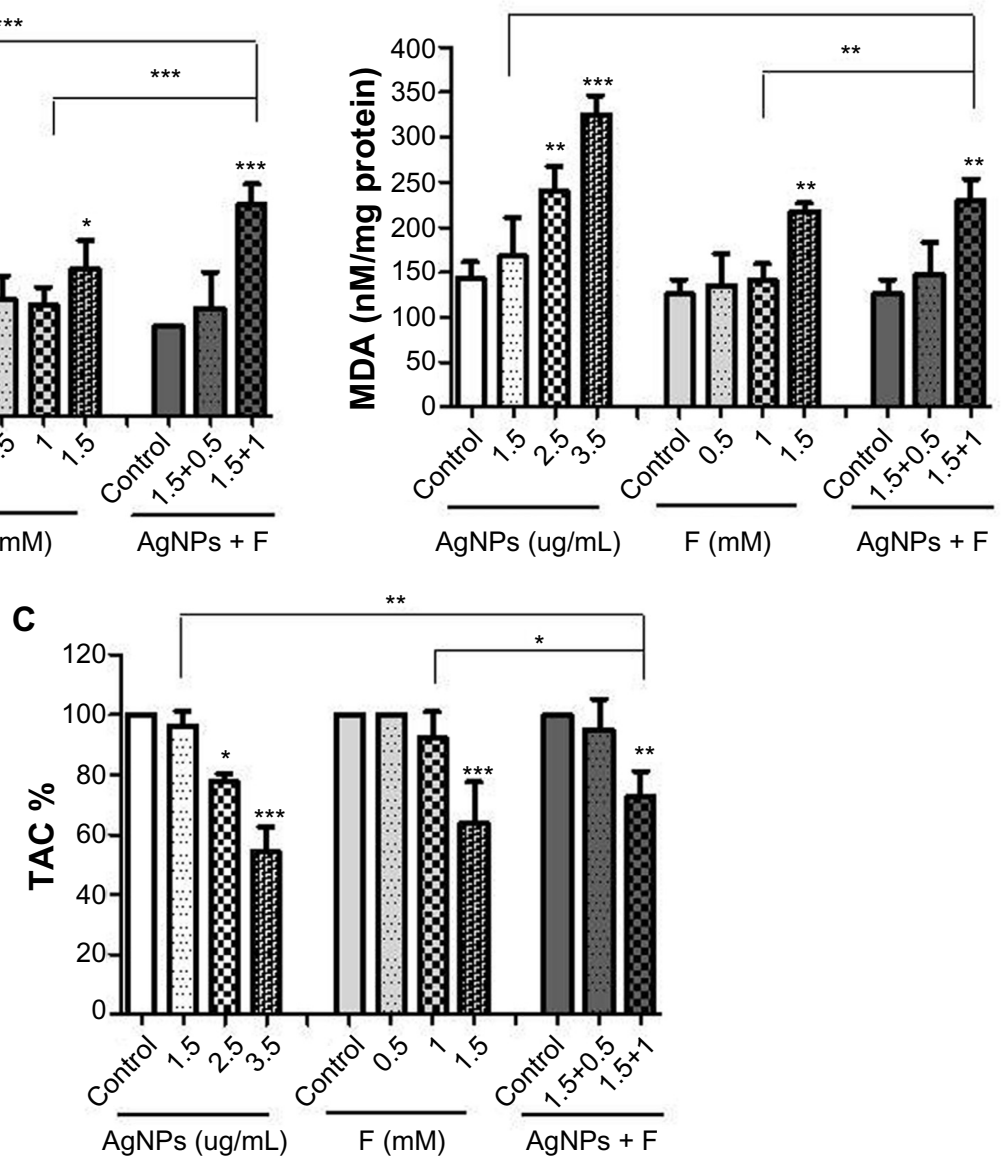

Figure 2 Induction of ROS and MDA along with reduction of TAC by AgNPs and F co-exposure in CRL-2014 cells. (A) CRL-2014 cells exposed simultaneously to both AgNPs and F produced significantly higher levels of ROS compared to control cells and AgNPs- and F-treated cells, respectively; (B) CRL-20I4 cells exposed simultaneously to both AgNPs and F produced significantly higher levels of MDA compared to control cells and AgNPs- and F-treated cells, respectively; (C) CRL-20I4 cells exposed simultaneously to both AgNPs and F produced significantly lower levels of MDA compared to control cells and AgNPs- and F-treated cells, respectively. Notes: $* P<0.05$; $* * P<0.01$; $* * * P<0.001$.

Abbreviations: AgNPs, silver nanoparticles; F, fluoride; MDA, malondialdehyde; ROS, reactive oxygen species; TAC, total antioxidant capacity. 

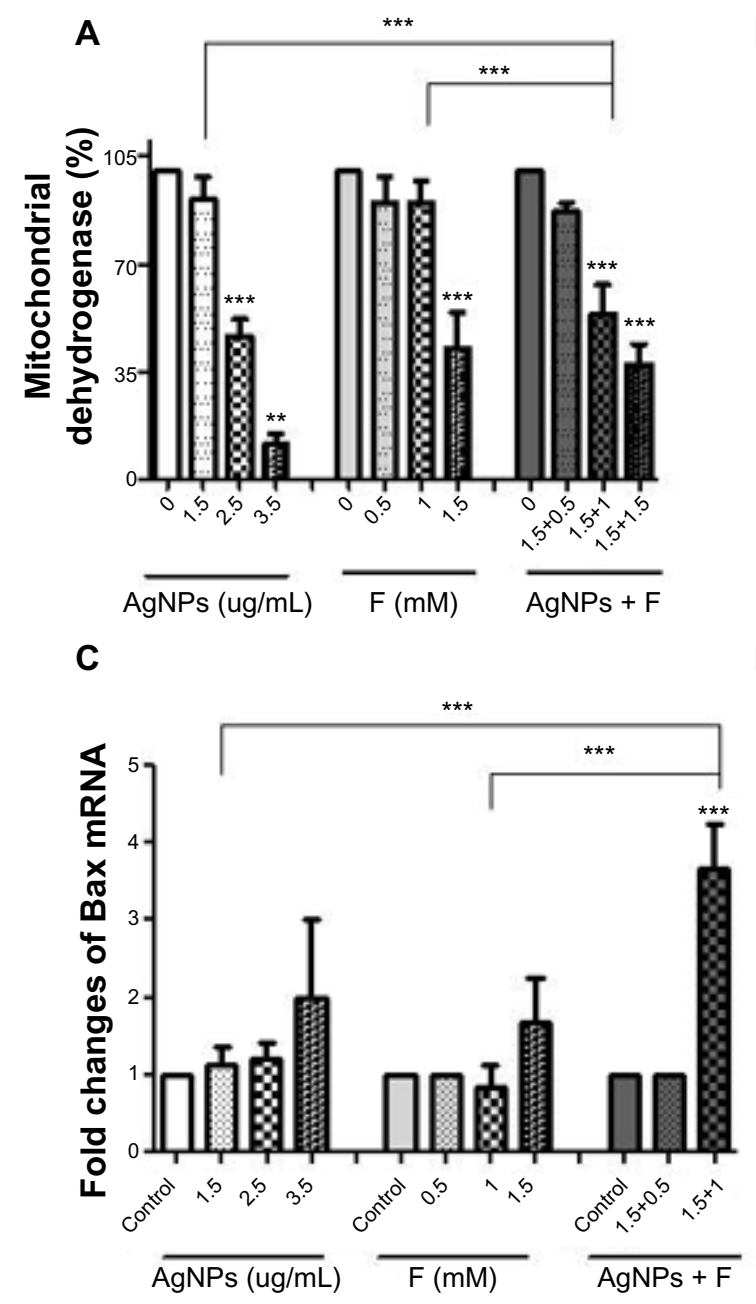

B

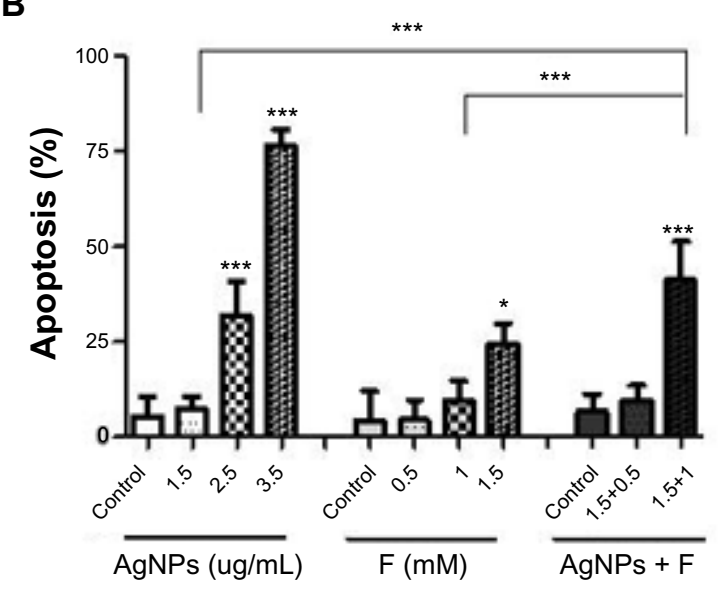

D

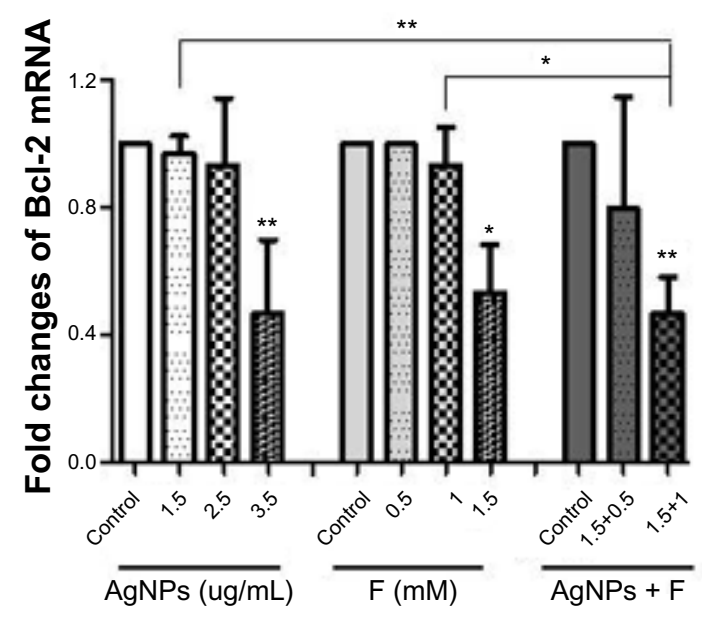

Figure 3 Effect of AgNPs and F co-exposure on cell survival. (A) Concentration-dependent toxicity of AgNPs and F on CRL-2014 cells. Cell viability was determined by the MTT assay. Co-exposure to both AgNPs and F significantly reduced cell survival compared to control cells and AgNPs- and F-treated cells, respectively; (B) increasing apoptotic effect of AgNPs and F on CRL-2014 cells. Apoptosis was determined by flow cytometry. Co-exposure to both AgNPs and F significantly increased apoptosis compared to control cells and AgNPs- and F-treated cells, respectively; (C) increasing levels of pro-apoptotic BAX gene. CRL-20I4 cells exposed simultaneously to both AgNPs and F showed significantly higher level of Bax compared to controls and AgNPs- and F-treated cells, respectively; (D) effect of AgNPs and F on the expression level of anti-apoptotic $\mathrm{Bcl}-2$ gene. Co-exposure to both $\mathrm{AgNPs}$ and $\mathrm{F}$ significantly reduced the level of $\mathrm{Bcl}-2$ compared to control cells and $\mathrm{AgNPs}$ - and $\mathrm{F}$-treated cells, respectively. Notes: $* P<0.05 ; * * P<0.01 ; * * * P<0.001$.

Abbreviations: AgNPs, silver nanoparticles; F, fluoride; mRNA, messenger RNA.

to apoptosis. We found that co-exposure to AgNPs and F did increase apoptosis significantly in CRL-2014 cells (Figure 3B). Indeed, the pro-apoptotic BAX gene was upregulated (Figure 3C) in contrast to the anti-apoptotic Bcl-2 gene (Figure 3D).

We also used phase-contrast microscopy to evaluate the effects of AgNPs and F on cellular morphology. No significant morphological changes were detected upon incubation of cells with AgNPs or F separately (Figure 4A and B). However, when cells were co-exposed to AgNPs and F, the corresponding phase-contrast micrographs revealed cell shortening and irregular cell shapes, which could indicate cell toxicity (Figure 4C and D).

\section{Activation of MAPK pathways and upregulation of inflammatory cytokines}

Having implicated the release of ROS in AgNP-F-induced fibroblast cell damage and apoptosis, we studied signaling pathways that may mediate these reactions, such as MAPK proteins, pro-inflammatory cytokines (IL-6 and IL-8), and a downstream effector, matrix metalloproteinase-9 (MMP-9). Western blot analysis showed that $\mathrm{F}$ promoted phosphorylation of p42/44 MAPK, an effect that was enhanced when AgNPs were added (Figure 5). AgNPs and F separately were able to upregulate IL-6, IL-8, and MMP-9 at gene level. In addition, we found that upregulation of gene expression was higher when gingival fibroblasts were co-exposed to 

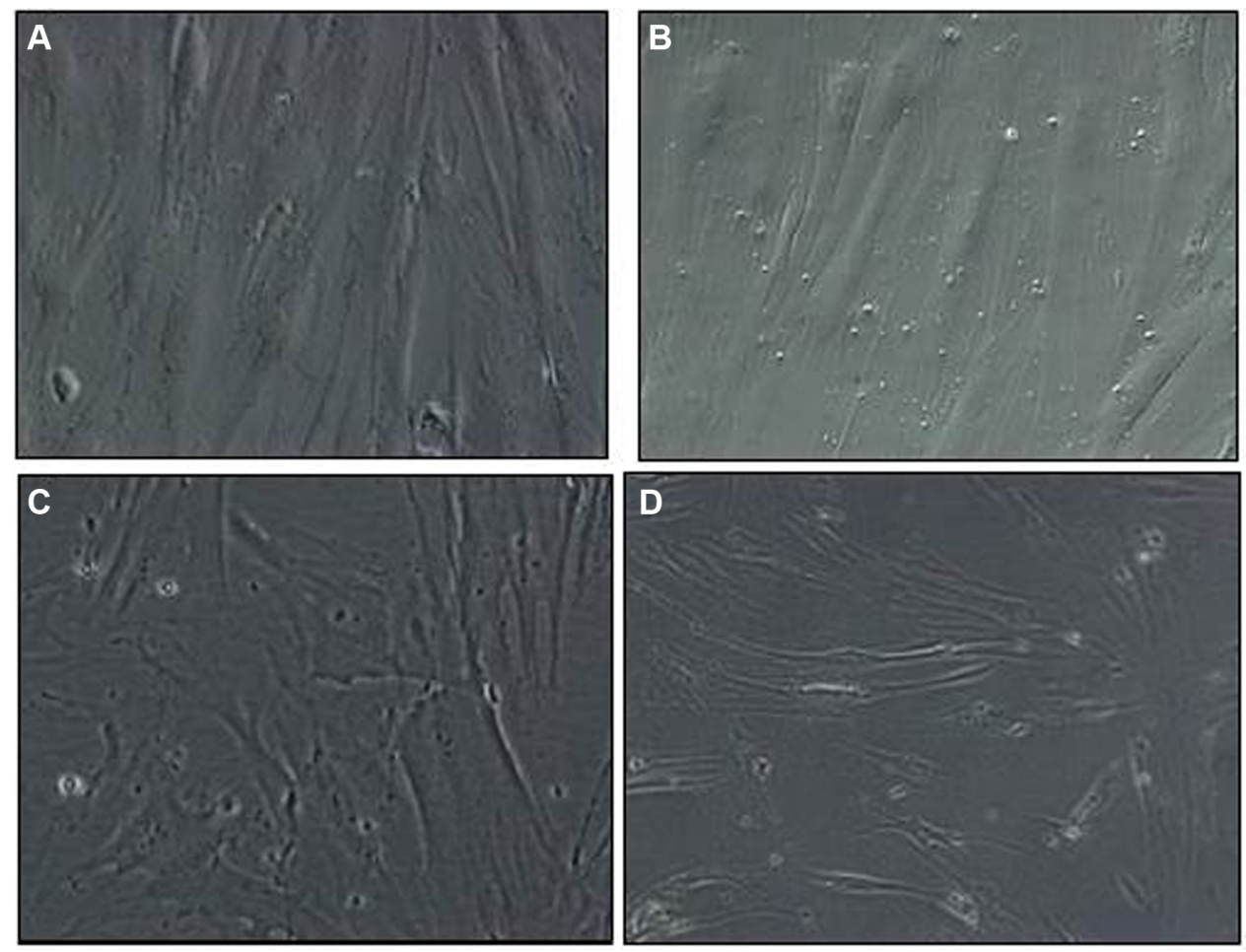

Figure 4 Morphological changes of CRL-20I4 exposed to AgNPs and F by phase-contrast microscopy. Cells co-exposed to AgNPs (I.5 $\mu$ g/mL) and F (I mM) for I 2 hours (C) and 24 hours (D) showed irregular cell shapes and cell shortening compared to AgNPs-treated cells (A) and F-treated cells (B).

Note: Original magnification was $20 x$.

Abbreviations: AgNPs, silver nanoparticles; F, fluoride.

AgNPs and F (Figure 5). Finally, co-exposure of CRL-2014 to AgNPs and $\mathrm{F}$ resulted in a significant release of MMP-9 into the cell culture supernatant (Figure 6).

\section{Discussion}

The major novel finding of this study is that AgNPs and F coexposure of gingival fibroblasts results in enhanced oxidative stress, triggering a cascade of inflammatory reactions that lead to apoptosis and impairment of cell viability.

Fluoride has been widely used in dentistry because it is an effective caries prophylactic agent. Nowadays, AgNPs are also being introduced as therapeutic antimicrobial agents in dental practice, although some concerns have emerged regarding their toxicological effects. ${ }^{5,16}$

Indeed, while the toxicological effects of both $\mathrm{F}$ and $\mathrm{AgNPs}$ had been previously investigated, our study is the first to analyze the outcome of pharmacological/toxicological interactions of a combination of two xenobiotics. Although positive interactions (additive or synergistic effects) were most likely to take place considering the individual profiles of the interacting agents, the opposite outcome, ie, antagonism had to be also considered. Our results clearly indicate that when used in combination,
AgNPs and F may cause increased gingival cytotoxicity. Indeed, we first showed that AgNPs were taken up by human gingival fibroblasts in the presence/absence of F. As AgNPs were internalized and mainly found in mitochondria that are vulnerable to oxidative stress, ${ }^{17,18}$ we studied the generation of ROS. Mitochondria dysfunction/damage by AgNPs has been previously found in human lung fibroblasts and liver cells. ${ }^{16,18}$ In physiology, ROS are produced during metabolic reactions and as this generation is potentially cytotoxic, they are generally neutralized by cell antioxidant systems (TAC). However, excessive ROS production may overwhelm the capacity of TAC leading to cellular dysfunction, and thus contributing to the pathogenesis of various human diseases. ${ }^{17}$

The results of studies examining the effects of AgNPs on TAC are not clear. Some researchers reported that AgNPs can act as free radical scavengers. ${ }^{19,20}$ In contrast, Chairuankitti et $\mathrm{al}^{21}$ found that the toxic effects of AgNPs on A549 cells are mediated via both ROS-dependent and ROS-independent mechanisms. Moreover, AshaRani et al ${ }^{16}$ showed that AgNPs caused mitochondrial dysfunction, namely the induction of ROS, which in turn set off DNA damage and chromosomal aberrations in normal human lung fibroblast cells. 
A

C
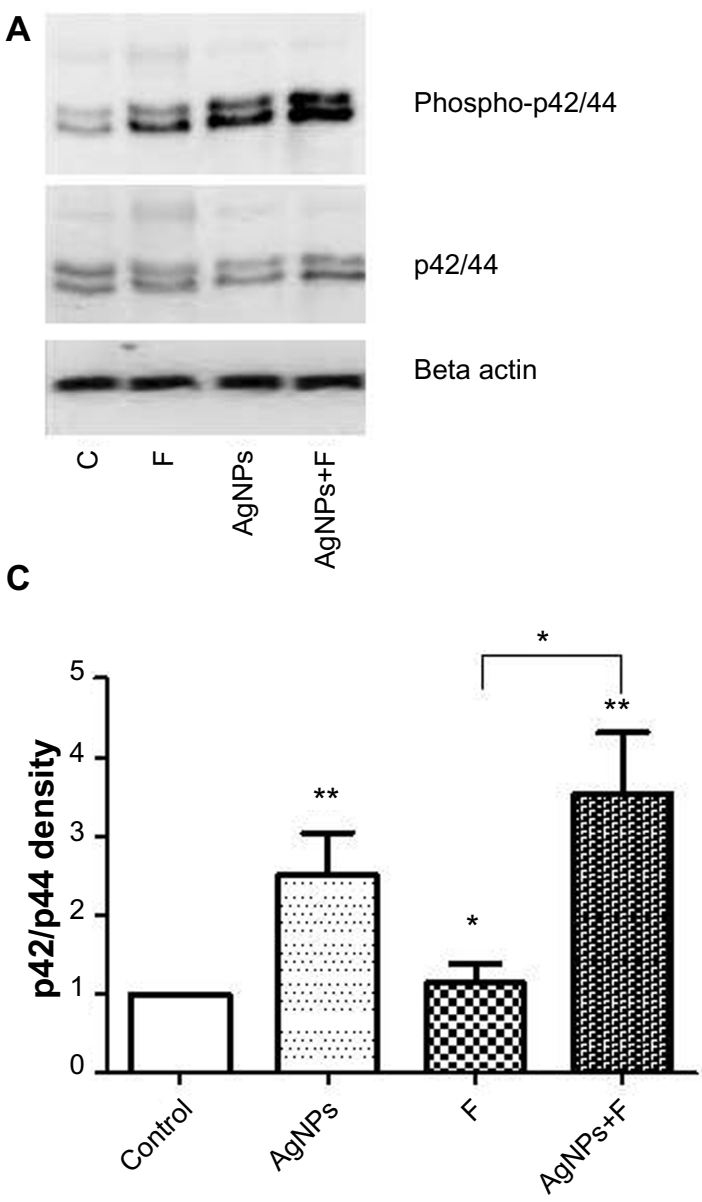
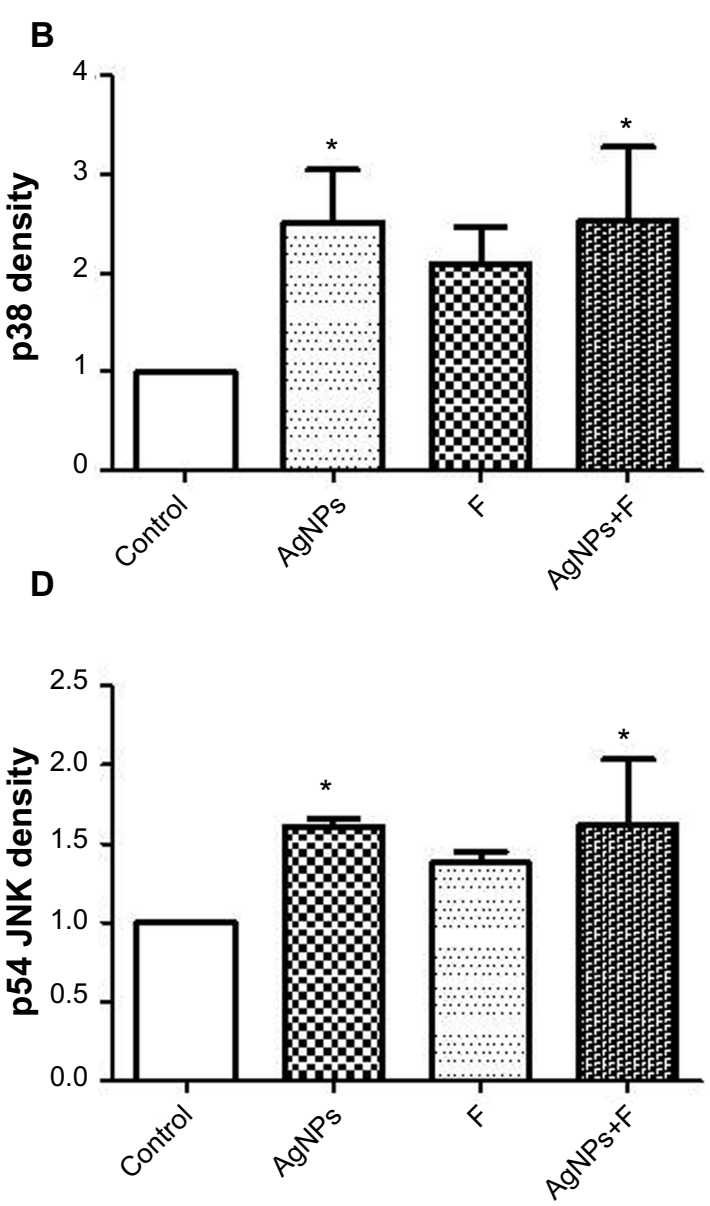

Figure 5 Effects of AgNPs and F on MAPK phosphorylation. (A) Representative Western blotting. Normalized densitometric values of phosphorylated p38 MAPK (B) p42/ P44 MAPK (C), and JNK MAPK (D).

Notes: $\mathrm{F}$ was only able to induce $\mathrm{p} 42 / 44$ phosphorylation $(* \mathrm{P}<0.05$ vs control). However, when AgNPs were also added, phosphorylation of $\mathrm{p} 42 / 44 \mathrm{MAPK}$ was enhanced ( $* P<0.05$ vs $\mathrm{F} ; * * P<0.0$ l vs control).

Abbreviations: AgNPs, silver nanoparticles; F, fluoride; MAPK, mitogen-activated protein kinases; vs, versus.

In addition, some studies have demonstrated that free radicals play a key role in fluoride-induced toxicity. ${ }^{10,11,22}$ In the current study, we found that both AgNPs and F were able to induce ROS generation, but interestingly, this effect was significantly higher when CRL-2014 cells were exposed to both AgNPs and F. These data correlated well with the unfavorable effects of AgNPs and $\mathrm{F}$ on antioxidant cell defenses. Indeed, we found a significant reduction of TAC when cells were exposed to various concentrations of AgNPs and F. These results are consistent with our previous studies in vivo. ${ }^{11}$

The cellular impact of unchecked increases in ROS levels is very significant. At high levels, ROS can lead to impaired physiological function through cellular damage of DNA, proteins, phospholipids, and other macromolecules. ${ }^{17}$ The cell membrane is one of the most susceptible sites to ROS damage. Lipid peroxidation can permanently impair fluidity and elasticity of the membrane, which can lead to cell rupture. Choi et $\mathrm{al}^{23}$ demonstrated an increase in the levels of MDA, a byproduct of cellular lipid peroxidation, in the liver of adult zebrafish after treatment with AgNPs. Moreover, F-induced lipid peroxidation was found in different cell culture, animal model, and epidemiological studies. ${ }^{11,24}$ Indeed, significant lipid peroxidation has also been reported in erythrocytes from children and adults suffering from endemic fluorosis. ${ }^{25}$ In the present study we found that the levels of MDA were increased in human gingival fibroblasts treated with AgNPs and $\mathrm{F}$. This effect was enhanced during co-exposure of cells to both xenobiotics. Again, these results correlated well with the overproduction of ROS. As ROS generation and lipid peroxidation could lead to cell death, we next studied cell viability. When cells were incubated with AgNPs $(1.5 \mu \mathrm{g} / \mathrm{mL})$ and $\mathrm{F}(1 \mathrm{mM})$ separately, no significant effects on cell viability were found. However, when cells were allowed to interact with the two xenobiotics at the indicated concentrations, cell viability was significantly reduced. Kleinsasser et a $l^{9}$ have previously found that $\mathrm{F}$ causes mucosal cell damage 
A

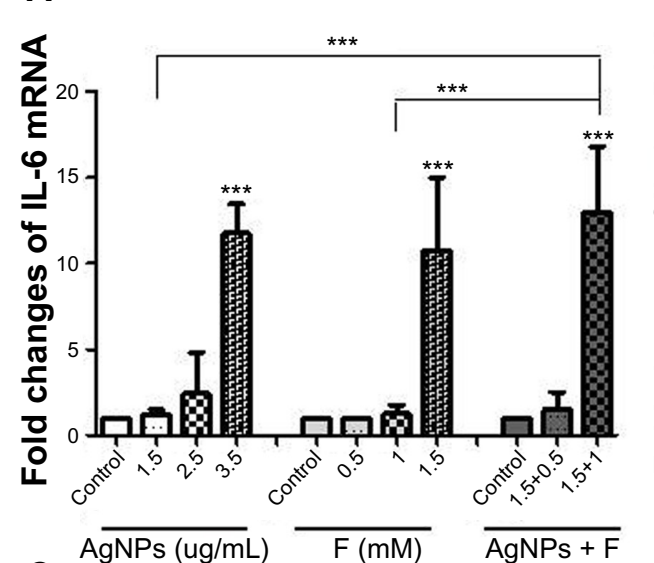

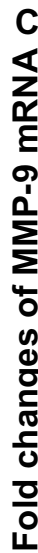

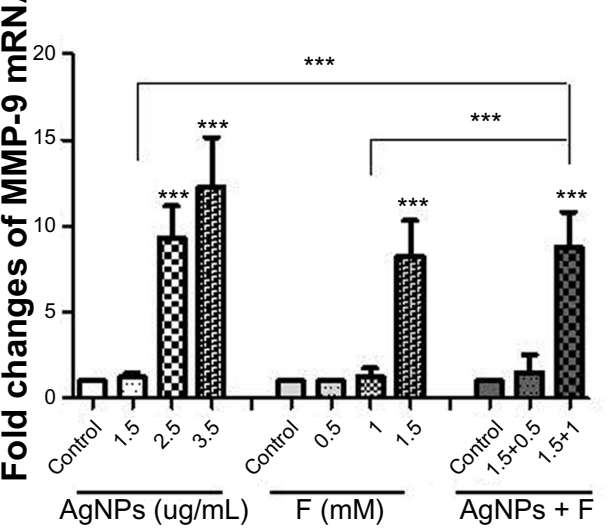

B

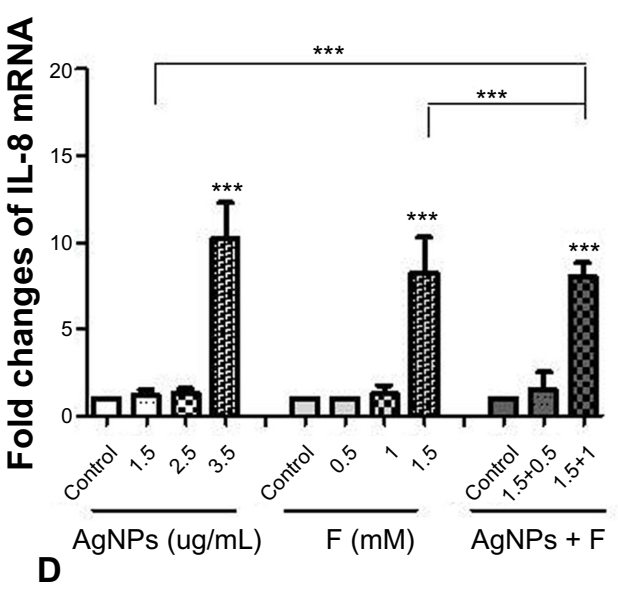

D

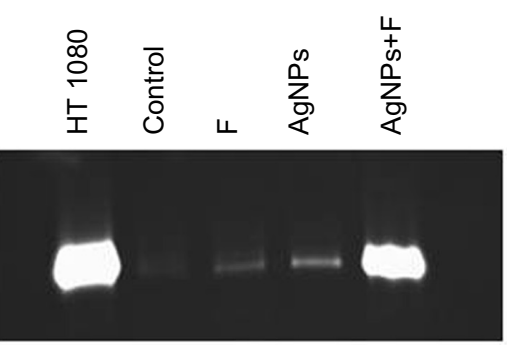

Figure 6 Effect of AgNPs and F on the expression level of inflammatory markers in CRL-20I4 cells. The gene expression of IL-6 (A), IL-8 (B), and MMP-9 (C) was investigated. CRL-20I4 cells exposed simultaneously to both AgNPs and F produced significantly higher levels of IL-6, IL-8, and MMP-9 compared to control cells and AgNPsand F-treated cells, respectively ( $* * * P<0.00 I$ ); (D) representative zymogram showing the gelatinolytic activity of MMP-9 in the conditioned media from CRL-20I4 exposed to $\mathrm{AgNPs}$ and $\mathrm{F}$ as in $(\mathbf{A})$.

Note: HTI080 conditioned media was run as an internal control.

Abbreviations: AgNPs, silver nanoparticles; F, fluoride; mRNA, messenger RNA; MMP, matrix metalloproteinase-9.

in a concentration-dependent manner. Tissue necrosis after subgingival irrigation with a solution of $\mathrm{F}$ has also been demonstrated. ${ }^{8}$ Finally, AgNPs $<20 \mathrm{~nm}$ increased cytotoxicity in human periodontal fibroblasts in a concentration- and time-dependent manner. ${ }^{5}$

This oxidant/antioxidant imbalance has previously been documented as an apoptotic mechanism of AgNP-mediated cytotoxicity. ${ }^{26}$ Therefore, we next studied whether AgNP and $\mathrm{F}$ could induce apoptosis. Several studies have shown that millimolar levels of $\mathrm{F}$ can induce apoptosis in many cell types, including hepatic cells, epithelial lung cells, human leukemia HL-60 cells, and ameloblast-lineage cells..$^{27-30} \mathrm{We}$ have also shown that $\mathrm{F}$ increases apoptosis in hippocampal and osteoblast-like cells. ${ }^{10}$ However, other mechanisms can be involved in F-mediated cell death, such as endoplasmic reticulum stress. ${ }^{31}$ Furthermore, AgNPs are able to induce cell death through apoptotic mechanisms in cultured cells and animal tissues. ${ }^{18,32,33}$ In the present study, we have found that co-exposure to AgNPs and $\mathrm{F}$ resulted in a significant increase in cell apoptosis.

As ROS generation could trigger the activation of different pathways involved in inflammation, we next studied the MAPK pathways. Generally, increased ROS production in a cell leads to the activation of $\mathrm{p} 42 / \mathrm{p} 44$, JNKs, or $\mathrm{p} 38$ MAPK. ${ }^{34,35}$ Diverse cellular functions, ranging from cell survival to cell death, are regulated by MAPK. P42/p44 activation seems to promote survival in most cell types but it has also been reported that induction of apoptosis may be mediated via $\mathrm{p} 42 / \mathrm{p} 44 .{ }^{35,36}$ The importance of the $\mathrm{p} 42 / \mathrm{p} 44$ MAPK pathway in mediating apoptosis has also been recently observed in other models of oxidant-induced apoptosis, including asbestosis, UV irradiation, and tumor necrosis factor. ${ }^{34-36}$ However, the other MAPK (JNK and p38) have been implicated primarily in the induction of apoptosis and inflammation after exposure to different agents. ${ }^{34,37}$ It has been found that AgNPs could activate p38 MAPK and JNK 
in vitro. ${ }^{18,38}$ In addition, $\mathrm{F}$ could also induce the activation of JNK and p42/44 MAPK in osteoclast cells. ${ }^{6,7}$ Our studies show that both AgNPs and F significantly increased the phosphorylation of p42/p44 and this effect is enhanced during co-exposure to both xenobiotics. Therefore, the activation of different MAPK by AgNPs and F could be cell dependent. Finally, this activation could lead to the upregulation of different proinflammatory cytokines. Therefore, we studied whether AgNPs and F were able to induce the upregulation of IL-6, IL-8, and MMP-9. Interestingly, the upregulation of both cytokines and MMP-9 was found when CRL-2014 cells were exposed to both AgNPs and F; Vandana and Reddy ${ }^{39}$ suggested that there is a strong association of periodontal disease in high-fluoride areas. It has also been found that high concentrations of $F$ resulted in the upregulation of MMP-2 and MMP-9 in pro-osteoblast cells. ${ }^{30}$ However, it has been also suggested that an oral hygiene regimen based on amine/ stannous fluoride-containing toothpaste is effective in reducing plaque-associated gingivitis and gingival inflammation. ${ }^{40}$ Of note, AgNPs cause inflammation in other cell types, such as liver cells both in vivo and in vitro. ${ }^{41,42}$

In conclusion, we have shown that co-exposure of gingival fibroblasts to AgNPs and F amplifies the noxious effects of the individual xenobiotics. The mechanism of this action may depend on increased generation of ROS or lipid peroxidation along with a decrease in TAC that could lead to cell death and inflammation. Further studies are warranted to establish the safety profile of these agents for further clinical applications.

\section{Acknowledgments}

This work was funded by Science Foundation Ireland (SFI) (05/FE1/B862 to MWR and SFI-RFP/BMT2781 to CM).

\section{Disclosure}

$\mathrm{CM}$ is an SFI Stokes lecturer. The authors have no other conflicts of interest to report.

\section{References}

1. Morones JR, Elechiguerra JL, Camacho A, et al. The bactericidal effect of silver nanoparticles. Nanotechnology. 2005;16(10):2346-2353.

2. Liao J, Anchun M, Zhu Z, Quan Y. Antibacterial titanium plate deposited by silver nanoparticles exhibits cell compatibility. Int $J$ Nanomedicine. 2010;5:337-342.

3. Allaker RP. The use of nanoparticles to control oral biofilm formation. J Dent Res. 2010;89(11):1175-1186.

4. Li F, Weir MD, Chen J, HH Xu. Comparison of quaternary ammoniumcontaining with nano-silver-containing adhesive in antibacterial properties and cytotoxicity. Dent Mater. 2013;29(4):450-461.

5. Hernández-Sierra JF, Galicia-Cruz O, Angélica SA, Ruiz F, PierdantPérez M, Pozos-Guillén AJ. In vitro cytotoxicity of silver nanoparticles on human periodontal fibroblasts. J Clin Pediatr Dent. 2011;36(1):37-41.
6. Everett ET. Fluoride's effects on the formation of teeth and bones, and the influence of genetics. $J$ Dent Res. 2011;90(5):552-560.

7. Karube H, Nishitai G, Inageda K, Kurosu H, Matsuoka M. NaF activates MAPKs and induces apoptosis in odontoblast-like cells. $J$ Dent Res. 2009;88(5):461-465.

8. Sjöström S, Kalfas S. Tissue necrosis after subgingival irrigation with fluoride solution. J Clin Periodontol. 1999;26(4):257-260.

9. Kleinsasser NH, Weissacher H, Wallner BC, Kastenbauer ER, Harréus UA. Cytotoxicity and genotoxicity of fluorides in human mucosa and lymphocytes. Laryngorhinootologie. 2001;80(4):187-190.

10. Inkielewicz-Stepniak I, Radomski MW, Wozniak M. Fisetin prevents fluoride- and dexamethasone-induced oxidative damage in osteoblast and hippocampal cells. Food Chem Toxicol. 2012;50(3-4):583-589.

11. Inkielewicz-Stepniak I, Czarnowski W. Oxidative stress parameters in rats exposed to fluoride and caffeine. Food Chem Toxicol. 2010;48(6): $1607-1611$.

12. Flora SJ, Mittal M, Pachauri V, Dwivedi N. A possible mechanism for combined arsenic and fluoride induced cellular and DNA damage in mice. Metallomics. 2012;4(1):78-90.

13. Pokrowiecki R, Zareba T, Mielczarek A, et al. Evaluation of biocidal properties of silver nanoparticles against cariogenic bacteria. Med Dosw Mikrobiol. 2013;65:197-206.

14. Thaweboon S, Thaweboon B, Chunhabundit P, Suppukpatana P. Effect of fluoride on human dental pulp cells in vitro. Southeast Asian J Trop Med Public Health. 2003;34:915-918.

15. Bradford MM. A rapid and sensitive method for the quantitation of microgram quantities of protein utilizing the principle of protein-dye binding. Anal Biochem. 1976;72:248-254.

16. AshaRani PV, Kah Mun GL, Hande MP, Valiyaveettil S. Cytotoxicity and genotoxicity of silver nanoparticles in human cells. ACS Nano. 2009;2(3):279-290.

17. Murphy MP, Holmgren A, Larsson NG, et al. Unraveling the biological roles of reactive oxygen species. Cell Metab. 2011;13(4):361-366.

18. Piao MJ, Kang KA, Lee IK, et al. Silver nanoparticles induce oxidative cell damage in human liver cells through inhibition of reduced glutathione and induction of mitochondria-involved apoptosis. Toxicol Lett. 2011;201(1):92-100.

19. Inbathamizha L, Mekalai Ponnub T, Jancy Mary E. In vitro evaluation of antioxidant and anticancer potential of Morinda pubescens synthesized silver nanoparticles. J Pharm Res. 2013;6(10):32-38.

20. Velavan S, Arivoli P, Mahadevan K. Biological reduction of silver nanoparticles using Cassia Auriculata flower extract and evaluation of their in vitro antioxidant activities. Nanosci Nanotechnol Int J. 2012;2(4):30-35.

21. Chairuankitti P, Lawanprasert S, Roytrakul S, et al. Silver nanoparticles induce toxicity in A549 cells via ROS-dependent and ROS-independent pathways. Toxicol in vitro. 2013;27(1):330-338.

22. Anuradha CD, Kanno S, Hirano S. Oxidative damage to mitochondria is a preliminary step to caspase-3 activation in fluoride-induced apoptosis in HL-60 cells. Free Radic Biol Med. 2001;31(3):367-373.

23. Choi JE, Kim S, Ahn JH, et al. Induction of oxidative stress and apoptosis by silver nanoparticles in the liver of adult zebrafish. Aquat Toxicol. 2010;100(2):151-159.

24. Xu H, Wang CH, Zhao ZT, Zhang WB, Li GS. Role of oxidative stress in osteoblasts exposed to sodium fluoride. Biol Trace Elem Res. 2008;123(1-3):109-115.

25. Shivarajashankara YM, Shivashankara AR, Gopalakrishna BP, Rao SH. Oxidative stress in children with endemic skeletal fluorosis. Fluoride. 2001;34(2):108-113.

26. Foldbjerg R, Olesen P, Hougaard M, Dang DA, Hoffmann HJ, Autrup H. PVP-coated silver nanoparticles and silver ions induce reactive oxygen species, apoptosis and necrosis in THP-1 monocytes. Toxicol Lett. 2009;190(2):156-162.

27. Lee JH, Jung JY, Jeong YJ, et al. Involvement of both mitochondrial- and death receptor-dependent apoptotic pathways regulated by Bcl-2 family in sodium fluoride-induced apoptosis of the human gingival fibroblasts. Toxicology. 2008;243(3):340-347. 
28. Yan Q, Zhang Y, Li W, Denbesten PK. Micromolar fluoride alters ameloblast lineage cells in vitro. J Dental Res. 2007;86:336-340.

29. Anuradha CD, Kanno S, Hirano S. Fluoride induces apoptosis by caspase-3 activation in human leukemia HL-60 cells. Arch Toxicol. 2000;74:226-230.

30. Slompo C, Buzalaf CP, Damante CA, et al. Fluoride modulates preosteoblasts viability and matrix metalloproteinases-2 and -9 activities. Braz Dent J. 2012;23(6):629-634.

31. Kubota K, Lee DH, Tsuchiya M, Young CS. Fluoride induces endoplasmic reticulum stress in ameloblasts responsible for dental enamel formation. J Biol Chem. 2005;280:23194-23202.

32. Kim S, Ryu DY. Silver nanoparticle-induced oxidative stress, genotoxicity and apoptosis in cultured cells and animal tissues. $J$ Appl Toxicol. 2013;33(2):78-89.

33. Hsin YH, Chen CF, Huang S, Shih TS, Lai PS, Chueh PJ. The apoptotic effect of nanosilver is mediated by a ROS- and JNK-dependent mechanism involving the mitochondrial pathway in NIH3T3 cells. Toxicol Lett. 2008(3);179:130-139.

34. Torres M, Forman HJ. Redox signaling and the MAP kinase pathways. Biofactors. 2003;17(1-4):287-296.

35. Plotnikov A, Zehorai E, Procaccia S, Seger R. The MAPK cascades: signaling components, nuclear roles and mechanisms of nuclear translocation. Biochim Biophys Acta. 2011;1813(9):1619-1633.
36. Wang X, Martindale JL, Liu Y, Holbrook NJ. The cellular response to oxidative stress: influences of mitogen-activated protein kinase signalling pathways on cell survival. Biochem J. 1998;333(2):291-300.

37. Ishikawa Y, Kitamura M. Dual potential of extracellular signal-regulated kinase for the control of cell survival. Biochem Biophys Res Commun. 1999;264(3):696-701.

38. Eom HJ, Choi J. p38 MAPK activation, DNA damage, cell cycle arrest and apoptosis as mechanisms of toxicity of silver nanoparticles in Jurkat T cells. Environ Sci Technol. 2010;44(21):8337-8342.

39. Vandana KL, Reddy MS. Assessment of periodontal status in dental fluorosis subjects using community periodontal index of treatment needs. Indian J Dent Res. 2007;18(2):67-71.

40. Trombelli L, Bottega S, Orlandini E, Scapoli C, Tosi M, Tatakis D. Response to a plaque control regimen on different levels of gingival inflammation. Minerva Stomatol. 2003;52(3):75-79.

41. Gaiser BK, Hirn S, Kermanizadeh A, et al. Effects of silver nanoparticles on the liver and hepatocytes in vitro. Toxicol Sci. 2013;131(2) 537-547.

42. Park EJ, Bae E, Yi J, et al. Repeated-dose toxicity and inflammatory responses in mice by oral administration of silver nanoparticles. Environ Toxicol Pharmacol. 2010;30(2):162-168.
International Journal of Nanomedicine

\section{Publish your work in this journal}

The International Journal of Nanomedicine is an international, peerreviewed journal focusing on the application of nanotechnology in diagnostics, therapeutics, and drug delivery systems throughout the biomedical field. This journal is indexed on PubMed Central, MedLine, CAS, SciSearch ${ }^{\circledR}$, Current Contents ${ }^{\circledR} /$ Clinical Medicine,

\section{Dovepress}

Journal Citation Reports/Science Edition, EMBase, Scopus and the Elsevier Bibliographic databases. The manuscript management system is completely online and includes a very quick and fair peer-review system, which is all easy to use. Visit http://www.dovepress.com/ testimonials.php to read real quotes from published authors. 